\title{
A FOURTH TYPE OF ERYTHROBLASTOSIS FOETALIS SHOWING HEPATIC CIRRHOSIS IN THE MACERATED FOETUS
}

\author{
A REPORT OF THREE CASES
}

(With coloured plate)

BY

J. L. HENDERSON, M.D., F.R.C.P.E.

(From the University Department of Child Life and Health and the Simpson Maternity Pavilion, Royal Infirmary, Edinburgh)

Three types of erythroblastosis foetalis are generally recognized, namely, anaemia haemolytica, which is the mildest form, icterus gravis, which is more serious, and hydrops foetalis, which is seldom compatible with independent life. The three cases recorded in this paper would seem to belong to a fourth type, not previously described, in which hydramnios is common and intrauterine death occurs some time before delivery. Foetuses of this type show little or no oedema, are severely macerated, and have a diffuse hepatic cirrhosis and splenomegaly: the placenta is greatly enlarged and pale pink in colour. This new type is the most severe manifestation of the disease, with the possible exception of cases of earlier intrauterine death resulting in miscarriage. Although an increased incidence of stillbirth is an acknowledged feature in sibships afflicted with erythroblastosis, the pathology of such cases has been neglected. Inaccessibility of material is the reason for this, as few workers on erythroblastosis have had the opportunity of studying cases in which intrauterine death has occurred.

During the last five years, I have observed fifty-two infants with erythroblastosis: nineteen recovered, twenty-four died and nine were stillborn. Twenty-nine of the series, who were born in a maternity hospital, were followed from birth and necropsies were performed in all the fatal cases. The relative frequency of the four types of the disease is given in table 1. Eighteen unobserved cases from the affected families are included.

TABLE 1

\section{THE TYPE DISTRIBLTION OF SEVENTY CASES OF ERYTHROBLASTOSIS FOETALIS}

$\begin{array}{cccccc}\text { TYPE } & \begin{array}{c}\text { ANAEMIA } \\ \text { HAEMOLYTICA }\end{array} & \begin{array}{c}\text { ICTERLS } \\ \text { GRAVIS }\end{array} & \begin{array}{c}\text { HYDROPS } \\ \text { FOETALIS }\end{array} & \begin{array}{c}\text { MACERATION } \\ \text { WITH HEPATIC } \\ \text { CIRRHOSIS }\end{array} \\ \begin{array}{l}\text { No. } \text {. } \\ \text { E }\end{array} & \ldots & 7 & 4 & 8 & 8\end{array}$




\section{Case reports}

Case 1. BABY O’M. Second pregnancy. Born 9/7/39. Non-hydropic macerated foetus.

Mother aged thirty-five years. Foetus of $7 \mathrm{lb} .1 \mathrm{oz}$. dead-born, at forty weeks, and severely macerated. Mother well throughout pregnancy, but had not felt life for a week before delivery when she had a heavy, sickly feeling. Wassermann reaction shortly after birth of this foetus, negative.

Necropsy. A well-developed male foetus showing advanced maceration. Head: No useful observations could be made owing to maceration. Thorax: Serous sacs contained blood-stained fluid, a normal feature in the macerated foetus. The lungs were unexpanded, with the appearance of healthy foetal lungs. The heart showed nothing of note. The thymus gland was small. Abdomen: Peritoneal sac contained blood-stained fluid. Alimentary tract showed nothing of interest.

LIVER. About average size, olive green, and showed bile-staining throughout. It was firmer and less diffluent than might have been expected in view of the advanced maceration, and slightly tough to cut.

SPLEEN. Greatly enlarged, measuring about three inches in diameter. It was soft and diffluent and extensively macerated.

Placenta. Weight $1 \mathrm{lb} .11 \mathrm{oz}$. (normal $1 \mathrm{lb} .5 \mathrm{oz}$.). 'Very unhealthy'appearance not described.

Kidneys and other organs showed nothing noteworthy. Bones: Ribs and long bones showed no macroscopic changes.

Histology. Haematoxylin and eosin sections of all the tissues examined showed advanced maceration.

LIVER. All cell structure was lost, but there was obviously a great increase of intercellular fibrous tissue reminiscent of congenital syphilis. This was confirmed with Azan's connective tissue stain (fig. 1).

SPLEEN. All cell structure was lost. No pathological changes could be detected.

Other pregnancies. FIRST PREGNANCY. Infant of $5 \mathrm{lb} .2 \mathrm{oz}$. born alive, at thirty-eight weeks, in 1937, apparently healthy and survived.

THIRD PREGNANCY. Infant of $5 \mathrm{lb}$. $10 \mathrm{oz}$. born alive, at thirty-nine weeks, in 1941, with severe jaundice. Placenta weighed $1 \mathrm{lb} .3 \mathrm{oz}$., but appearance not mentioned. Liver and spleen enlarged. Numerous subcutaneous ecchymoses. Three hours after birth prothrombin index 34 per cent. and haemoglobin 43 per cent. (Sahli). Reticulocytes greatly increased. Death occurred thirty-seven hours after birth. The usual features of icterus gravis were seen at necropsy. Icteric index of post-mortem blood serum was 254 . Microscopic examination of the liver showed the usual features of erythroblastosis, most of the erythropoietic foci were chiefly composed of large primitive erythroblasts. There was also some increase in the intercellular reticulum throughout the liver lobules, so that the cell columns were more separated from each other than usual. The portal tracts contained about the normal amount of fibrous tissue. There was no fibrosis in the spleen.

Case 2. BABY S. Third pregnancy. Born 14/9/41. Slightly hydropic macerated foetus.

Mother aged thirty-five years. Foetus of $5 \mathrm{lb} .10 \mathrm{oz}$. dead-born, at thirtysix weeks, and severely macerated. Mother had hydramnios for about the last six weeks of the pregnancy and had not felt life for the last two weeks. Wassermann reaction negative.

Necropsy. A small male foetus. Abdomen distended, but not tense. There was some oedema of face and head. Advanced maceration was present. Head: Nothing pathological recognized. Brain had undergone autolysis and 
was semi-fluid. Thorax: Serous sacs contained a quantity of blood-stained fluid not notably in excess of that invariably found in the macerated foetus. The lungs showed nothing to note. The heart looked a little above the appropriate size; it was dilated and flaccid owing to maceration. Abdomen: Peritoneal sac contained a large quantity of blood-stained fluid definitely in excess of the amount usually found in a macerated foetus. The alimentary tract showed nothing of interest.

LIVER. Moderately enlarged, yellowish-brown, fairly soft to the touch, but definitely a little tough to cut. Its surface was perfectly smooth. It was much less diffluent than might have been expected from the stage of maceration that had been reached, and had kept its consistency much better than any of the other organs. Its colour was quite unlike the usual dull pink of ordinary macerated livers. The appearance suggested that there might be some fine diffuse fibrosis.

SPLEEN. Much enlarged, being nearly three inches in diameter. It had undergone autolysis and was soft and diffluent.

Placenta. Weighed $2 \mathrm{lb} .9 \mathrm{oz}$. (normal $1 \mathrm{lb} .5 \mathrm{oz}$.) and had a pale pink colour; no other observations recorded.

Other organs showed nothing of interest.

Histology. LIVER. Haematoxylin and eosin sections showed advanced maceration; no cell structure or nuclear staining remained. A diffuse, fairly uniform, fine intercellular fibrosis was visible and confirmed by application of Masson's connective tissue stain (fig. 2). It was a little denser in some parts than in others, but these bore no relation to zones of the hepatic lobule.

SPLEEN. Apart from autolytic changes, did not show anything of interest.

Sections of all tissues stained by Dobell's method did not reveal any spirochaetes.

Previous pregnancies. FirSt PREgNanCY. Infant of $8 \mathrm{lb} .8 \mathrm{oz}$. born alive, at forty weeks, in 1933, apparently healthy and survived.

SECOND PREGNANCY. Infant of $8 \mathrm{lb}$. $3 \mathrm{oz}$. born alive, at forty weeks, in 1938, with severe jaundice. Placenta weighed $1 \mathrm{lb} .10 \mathrm{oz}$; appearance not mentioned. Liver and spleen enlarged. Haemoglobin 84 per cent. (Sahli), reticulocytes 35 per cent. and many nucleated erythrocytes. Death occurred thirty-eight hours after birth. Necropsy showed the usual features of icterus gravis and the occasional one of kernikterus. Microscopic examination of the liver showed excessive erythropoiesis, many of the erythroblasts being of a primitive type. There was no fibrosis in either liver or spleen.

Case 3. BABY T. Seventh pregnancy. Born 15/9/41. Non-hydropic macerated foetus.

Mother aged twenty-eight years. Foetus of $6 \mathrm{lb}$. $2 \mathrm{oz}$. dead-born, at thirty-eight weeks, and severely macerated. Mother felt very well throughout pregnancy, but had not felt life for ten days before delivery. Some hydramnios was observed on admission four days before delivery. Wassermann and Kahn reactions were negative after provocative injection during this pregnancy. In spite of this, a course of anti-syphilitic treatment was contemplated when the result of this pregnancy became known.

Necropsy. A small male infant showing advanced maceration. Head: Nothing of interest was found. Thorax: Organs showed the usual appearance of maceration. Abdomen: Peritoneal sac contained a quantity of blood-stained fluid, a common feature in the macerated foetus. The alimentary tract showed nothing to note.

LIVER. A little enlarged. It was light brown in colour with a greenishyellow tinge suggesting jaundice. It was not hard but seemed slightly tough to cut. Autolysis associated with maceration had not caused it to disintegrate 
as much as might have been expected and it was not diffluent. It was quite smooth on the outer surface.

SPLEEN. Enlarged to about two inches in length. It was soft but not diffluent.

Placenta. Weight $2 \mathrm{lb} .15 \mathrm{oz}$. (normal $1 \mathrm{lb} .5 \mathrm{oz}$.). It was very thick and had a pale pink colour.

Other organs showed nothing noteworthy.

Histology. Liver. Cell structure destroyed by maceration. No nuclear staining. A diffuse, fine, intercellular fibrosis was shown to be fairly uniform and abundant with Masson's stain (fig. 3). Haemopoietic foci not recognizable. Sections of liver and spleen stained by Dobell's method showed no spirochaetes.

SPLEEN. Cell types not recognizable although a certain amount of nuclear staining retained. No fibrosis.

Placenta. Villi thickened; relatively narrow intervillous spaces. The most striking feature was an abnormal persistence of Langhans' layer of cells. The overlying syncytial cells were unusually large and numerous, frequently forming nests. No erythropoietic foci were observed, but numerous erythroblasts were seen in the vessels. The stroma was oedematous and many of the stromal cells, which were increased in number, showed enlarged, palely staining nuclei.

SUPRARENALS: A few foci of erythroblasts in the medulla.

Previous pregnancies. FIRST PREGNANCY. Infant of $8 \mathrm{lb}$. born alive, at forty weeks, in 1933, apparently healthy and survived.

SECOND PREGNANCY. Infant of $9 \frac{1}{2} \mathrm{lb}$. born alive, at forty weeks, in 1935, apparently healthy and survived.

THIRD PREGNANCY. Infant of $6 \frac{1}{2} \mathrm{lb}$. born alive, at forty weeks, in 1936, became ' extremely bloodless' and died aged three weeks. This infant probably died from erythroblastosis of the anaemia haemolytica type.

FOURTH PREGNANCY. Infant of $6 \frac{1}{2} \mathrm{lb}$. born alive, at forty weeks, in 1938, and died aged two days. No evidence obtainable, but may well have died from erythroblastosis.

FIFTH PREGNANCY. Foetus of unknown weight stillborn, at thirty-two weeks, in 1939, when mother suffered an antepartum haemorrhage. Foetus appeared normal, but may have been affected with erythroblastosis.

SiXTH PREGNANCY. Foetus of unknown weight dead-born, at forty weeks, in 1940, in a macerated condition. Attending doctor felt sure it was syphilitic owing to its appearance and that of the placenta. This can certainly be regarded as a case of erythroblastosis in view of the necropsy findings in the foetus and placenta of the following pregnancy described above.

\section{Comment}

A family history of erythroblastosis, and identical pathological features in the three cases recorded in this paper, proves beyond all reasonable doubt that they represent a type of erythroblastosis not previously described as a definite entity. The principal features have already been mentioned, but the degenerative changes in the liver in this, and in less severe forms of the disease, merit further consideration.

Degenerative changes in the parenchymal cells of the liver, sometimes amounting to actual necrosis, are a common feature in icterus gravis and hydrops foetalis. Cirrhosis, also, is common in infants with icterus gravis who succumb after a few weeks of life, but is only occasionally seen when death occurs earlier. 


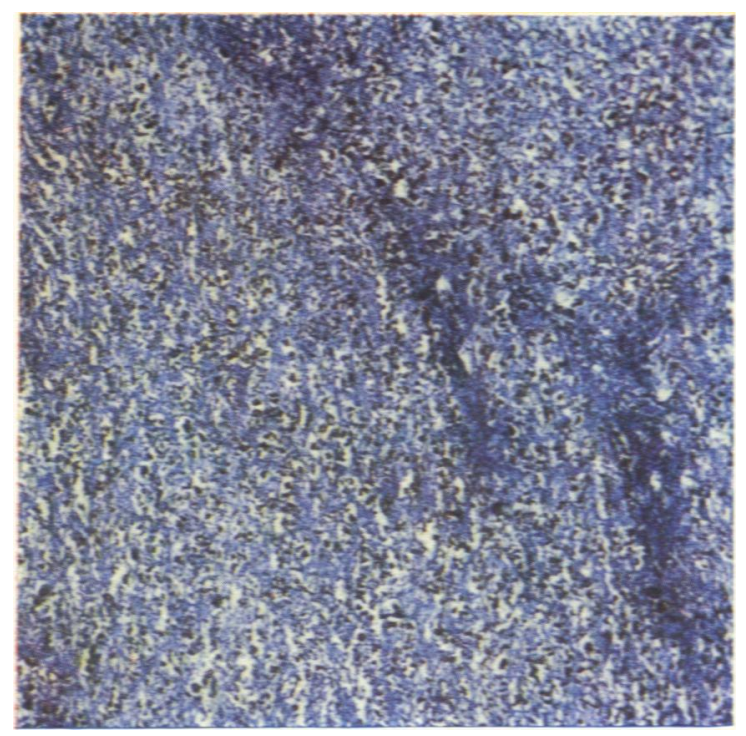

Fig. 1.-Case 1. (Liver 75.) Azan`s connective tissue stain.

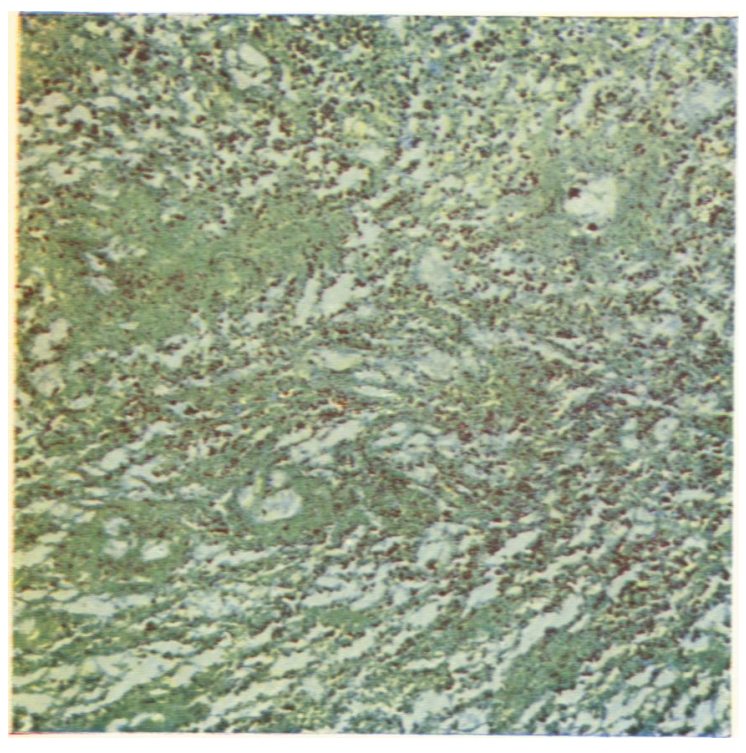

Fig. 2.-Case 2. (Liver 55.) Masson's connective tissue stain.

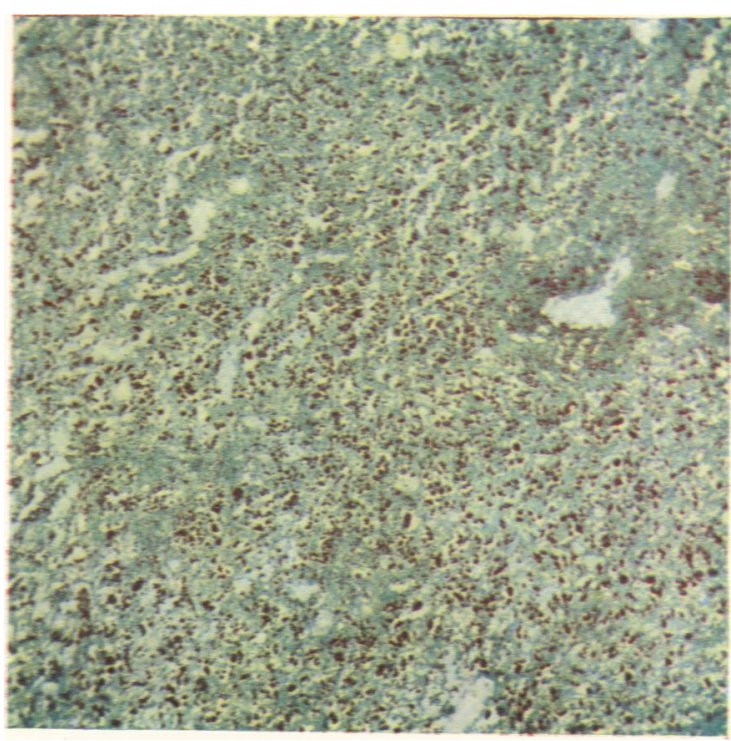

FIg. 3.-Case 3. (Liver 55.) Masson's connective tissue stain. 
Little attention had been paid to hepatic cirrhosis in erythroblastosis until its frequency was pointed out by Hawksley and Lightwood (1934). In a series of fifteen cases of icterus gravis they found hepatic cirrhosis in seven out of nine infants who had survived for longer than five weeks, but it did not occur in any of the six who died earlier. Slight degrees of cirrhosis have been recorded, however, in cases of icterus gravis in which death occurred within a few days of birth, and also in hydrops foetalis.

In the present series of thirty-three cases of erythroblastosis examined at necropsy hepatic cirrhosis was demonstrated in all three of the severely macerated foetuses, in one of the seven with hydrops foetalis and in seven of the twenty-three with icterus gravis. In the icterus gravis group, the incidence was much higher in those surviving for a few weeks. In the severely macerated foetuses, described in this paper, autolytic changes had destroyed all cell structure in the liver and the cirrhosis was of the diffuse intercellular type (fig. 1 to 3 ). In several of the hydrops and icterus gravis cases, severe degenerative changes, sometimes amounting to actual necrosis, were seen in the parenchymal cells of the central zone of the hepatic lobules. Fibrosis had usually begun in the necrotic areas. Two infants, who died of icterus gravis within two days of birth. showed a fine, diffuse intercellular cirrhosis, and portal cirrhosis was observed in a few cases. Occasionally, those cases showing a predominantly central or portal cirrhosis also showed a slight increase of intercellular reticulum throughout the lobule.

The pronounced degree of hepatic cirrhosis in the severely macerated foetuses, described in this paper, proves that erythroblastosis may run a long intrauterine course. This type of the disease bears a close superficial resemblance to congenital syphilis, but closer examination of the foetus and placenta renders differentiation easy. It is regrettable that such a common foetal and neonatal disease as erythroblastosis should not be generally recognized. The more severe types are still usually regarded as congenital syphilis, and the unfortunate mothers condemned as syphilitic in spite of negative serological reactions (vide case 3 ).

It is difficult to determine the relative frequency of this newly-described type of erythroblastosis, as affected foetuses are often not examined and therefore remain undetected. It may be more common than either hydrops foetalis or anaemia haemolytica.

\section{Summary}

Three cases of erythroblastosis in macerated foetuses are recorded.

The principal features are severe maceration, diffuse hepatic cirrhosis, splenomegaly and a large, pale pink placenta.

These cases are regarded as typical examples of a fourth clinical type of erythroblastosis which is the most severe manifestation of the disease.

Attention is drawn to the close superficial resemblance to congenital syphilis.

Thanks are due to Prof. Charles McNeil for his enthusiastic interest, and to Dr. Agnes Macgregor for the admirable pathological reports and also to $\mathrm{Mr}$. 
T. C. Dodds for the photographs. The Carnegie Trust for the Universities of Scotland generously helped towards the cost of the coloured illustrations.

\section{REFERENCE}

Hawksley, J. C., and Lightwood, R. (1934). Quart. J. Med., 3, 155.

\section{Addendum}

Since this paper was written, another case of erythroblastosis in a macerated foetus has been observed. The features, which were identical with those in the three original cases, are recorded below.

Case 4. BABY Y. Fifth pregnancy. Born 12/12/41. Slightly hydropic macerated foetus.

Mother aged thirty-seven years. Foetus of $9 \mathrm{lb} .5 \mathrm{oz}$. dead-born, at thirtyeight weeks, and severely macerated. Mother felt very well until two weeks before delivery when she developed toxic symptoms. A severe degree of hydramnios developed during this time and no life was felt for ten days before delivery. Labour was induced by rupturing the membranes, when seven pints of brown-coloured liquor amnii escaped. Another two to three pints of fluid drained away after the spontaneous birth of the foetus two hours 'later. Wassermann reaction negative.

Necropsy. A large female foetus. A little oedema of the face and upper part of the thorax was present, but there was none in the limbs. The abdomen was enlarged, but the abdominal wall was quite lax. Advanced maceration was present. Head: Nothing pathological recognized. Thorax: Pleural sacs contained a considerable quantity of blood-stained fluid not notably in

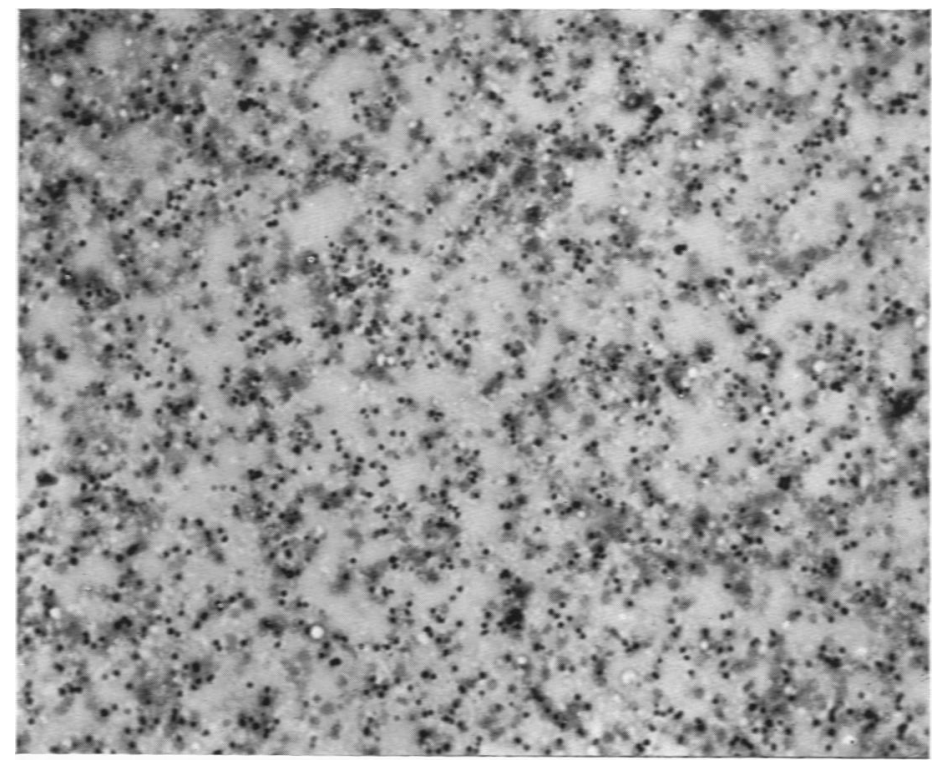

FIG. 4.-Case 4. (Blood, post-mortem, $\times 110$.) Leishmann's stain. Erythroblasts are exceedingly numerous. In addition to the normoblasts with darkly staining, pyknotic nuclei, there are many megaloblasts with larger, palely staining nuclei. 
excess of that commonly found in the macerated foetus. Pericardial sac contained only a small quantity of blood-stained fluid. Lungs showed nothing noteworthy. Heart seemed a little enlarged, but this may have been the result of relaxation of the wall owing to maceration. Abdomen: Peritoneal sac contained only a small quantity of blood-stained fluid. Alimentary tract showed nothing of interest.

LIVER. About average size, weighed $180 \mathrm{gm}$. Rather firmer than expected in view of the degree of maceration present, slightly greenish-brown and definitely, though slightly, tough to cut. There was no visible fibrosis and the outer surface was perfectly smooth.

SPLEEN. Immensely enlarged, weighed $70 \mathrm{gm}$. and measured fully 5 in. in length. Its lower pole lay to the right of the middle line and much of the abdominal enlargement was due to its great size. It was soft, lightish red and showed advanced maceration.

Placenta. Weight $3 \mathrm{lb} .15 \frac{1}{2}$ oz. (normal $1 \mathrm{lb} .5 \mathrm{oz}$.). Diameter $10 \mathrm{in.}$ Thickness $1 \frac{1}{4}$ in. Pale pink colour.

Other organs showed nothing of interest.

Histology. LIVER. Autolysis advanced with loss of all cell structure and nuclear staining. There was a diffuse fine fibrosis which was present everywhere, but varied a little in degree from place to place, although it had no zonal distribution. It was readily perceptible in sections stained with haematoxylin and eosin, but was shown to much greater advantage by Masson's connective tissue stain.

SPLEEN. Very little nuclear structure remained. No fibrosis.

BLOOD. A film of heart blood had resisted autolysis better than might have been expected (fig. 4). It showed a great increase in the number of nucleated red cells, including many very primitive forms.

Placenta. Histological characters comparable with those seen in case 3. Villi enlarged with relatively narrow intervillous spaces. The characteristic persistence of Langhans' cells could be seen here and there. The syncytial cells were increased in number, frequently forming clusters, and were often enlarged. The stroma had an oedematous appearance in some places and many of the cells, which were increased in number, showed enlarged, palely staining nuclei. No erythropoietic foci were observed, but numerous erythroblasts were seen in the vessels.

Previous pregnancies. FIRST PREgnanCY. Miscarriage.

SECOND PREGNANCY. Infant of $7 \mathrm{lb}$. born alive, at forty weeks, in 1933. Apparently healthy in infancy. Developed poliomyelitis later.

THIRD PREGNANCY. Infant of unknown weight stillborn, at forty weeks, in 1938. Anencephaly. No autopsy.

FOURTH PREGNANCY. Infant of $3 \mathrm{lb} .13 \mathrm{oz}$. born alive, at twenty-eight weeks, in 1940, following an antepartum haemorrhage. The placenta weighed $1 \mathrm{lb} .4 \mathrm{oz}$. but no further details are available. The infant died aged 11 hours. Nothing of much interest was found at autopsy. The cerebral hemispheres were excessively congested and a considerable degree of haemorrhage was seen in the posterior part of the falx cerebri. The lungs were almost completely atelectatic and sank in water. No histological examination was made. 